\title{
EVALUATION OF WEAR AND SURFACE ROUGHNESS OF DIFFERENT CAD/CAM MONOLITHIC CERAMIC MATERIALS
}

\author{
Mazen A. Attia*
}

\begin{abstract}
Purpose: To evaluate the wear and surface roughness of different CAD/CAM monolithic ceramic materials opposing monolithic zirconia.

Material and Methods: Twenty-seven rectangular-shaped specimens were milled from different ceramic materials by using a precision saw and divided ( $\mathrm{n}=9)$ into 3 groups: group ZLS, zirconia-reinforced lithium silicate; group LD, lithium disilicate glass ceramic; and group ZR, 4-mol yttria-stabilized tetragonal zirconia polycrystal (4Y-TZP). Antagonist material were milled from a partially sintered 4Y-TZP blank with a CAD/CAM system. Two-body wear test was performed in a mastication simulator. The wear of the specimens and antagonists was determined by calculating the weight loss. The surface roughness of the specimens and antagonists before and after wear testing was analyzed by using a digital image analysis software program. The surfaces of ceramic specimens and antagonists were inspected by using scanning electron microscopy. Data were statistically analyzed by using 1-way ANOVA and the Tukey post hoc test $(p=0.05)$.
\end{abstract}

Results: One-way ANOVA revealed significant amount of weight loss for all ceramic types $(p<0.05)$. No statistically significant differences were found between the different ceramic types when comparing their percentage change of weight $(p=0.544)$. As for the surface roughness, oneway ANOVA revealed significant increase in surface roughness for all ceramic types after chewing simulation $(p<0.05)$. No statistically significant differences were found between the different ceramic types when comparing their percentage change roughness $(p=0.251)$.

Conclusions: The different types of tested ceramics showed similar wear resistance when opposed to monolithic zirconia

KEYWORDS: Ceramics; Wear; Zirconia; Roughness

\section{INTRODUCTION}

The acceptable esthetic and mechanical properties, excellent biocompatibility, and less wear to the opposing dentition of ceramic materials have led to an increasing popularity of monolithic ceramic restorations, allowing for a conservative tooth preparation particularly in patients with parafunctional habits and eliminating chipping

\footnotetext{
* Associate Professor, Fixed Prosthodontics Department, Faculty of Dentistry, Beni-Suef University, Beni-Suef, Egypt.
} 
of veneering porcelain. ${ }^{1-6}$ To save clinician and processing time, different computer-aided design and computer-aided manufacturing (CAD/CAM) ceramic materials, including 4-mol yttria-stabilized tetragonal zirconia polycrystal (4Y-TZP), zirconiareinforced lithium silicate (ZLS), ${ }^{7}$ and lithium disilicate have been recently introduced. ${ }^{1,5}$ The development of these materials along with advanced processing technologies enable their use to fabricate veneers, inlays, onlays, hybrid implant abutments, anterior or posterior crowns, and short span fixed partial dentures. ${ }^{1}$

The wear rate of ceramic restorations opposing the natural dentition and other restorations should be closer to that of enamel, which is approximately 20 to $40 \mu \mathrm{m}$ per year. ${ }^{8,9}$ Excessive wear results in poor esthetics, loss of vertical dimension, and reduced masticatory function. ${ }^{10-13}$ In clinical practice, ceramic restorations may be opposed by enamel, composite, amalgam, ceramic, or full anatomical zirconia during occlusal movements. ${ }^{14}$ However, the wear of ceramic materials opposing zirconia have been questioned especially for monolithic restorations. ${ }^{15}$

A more translucent 4Y-TZP materials containing tetragonal and cubic grains have been introduced with improved properties. ${ }^{1}$ Zirconia manufacturers increased the yttria content from 3 to $5 \mathrm{~mol} \%$ enabling low phase transformation toughening where the tetragonal phase can be retained at room temperature; however, accomplishing high translucency resulted in diminished fracture toughness of 2.5 to $3.5 \mathrm{MPa} \cdot \mathrm{m}^{1 / 2}$ and a flexural strength of approximately 700 to $800 \mathrm{MPa} .^{16,17}$ Lithium disilicate materials have gained its popularity because of their better esthetics. The material contains an interlocking microstructure of a metasilicate phase incorporated in a glass matrix and is provided in a partially crystallized state to expedite milling. After milling, the material is crystallized in a furnace at $850^{\circ} \mathrm{C}$ under vacuum resulting in a fracture toughness of 2.25 $\mathrm{MPa} \cdot \mathrm{m}^{1 / 2}$ and a flexural strength of 360 to $500 \mathrm{MPa} .{ }^{18}$
Recently, ZLS ceramics containing $10 \%$ by weight zirconia in a silica-based glass matrix have been introduced to reinforce the ceramic structure by preventing crack propagation. ${ }^{19}$ The manufacturer has claimed that this innovative material combines the properties of zirconia and glass ceramics resulting in improved esthetics and mechanical properties. ${ }^{20,21}$ In addition, the material is provided in a crystallized state to expedite milling and polishing resulting in a fracture toughness of $2.65 \mathrm{MPa} \cdot \mathrm{m}^{1 / 2}$ and a flexural strength of $210 \mathrm{MPa}$; however, an additional crystallization improved the flexural strength to $370 \mathrm{MPa}{ }^{10,22}$

The wear properties of zirconia, ${ }^{23-28}$ lithium disilicate, ${ }^{29-31} \mathrm{ZLS},{ }^{30}$ when opposing antagonist enamel have been reported. ${ }^{32,33}$ D' Arcangelo et $\mathrm{al}^{10}$ reported comparable antagonist and material wear for lithium disilicate and ZLS. Preis et $\mathrm{al}^{34}$ reported that the wear of translucent zirconia was less than lithium disilicate. The clinical evaluation of wear of ceramic materials is complicated and time consuming ${ }^{35}$; therefore, dual axis mastication simulators and methods have been developed to evaluate the wear of different ceramic materials and to simulate clinical conditions; thus, elucidating criteria for proper selection of the restorative material..$^{36-38}$

Data on the wear of CAD/CAM monolithic ceramic materials opposing monolithic zirconia are lacking. Therefore, this in-vitro study was aimed to evaluate the wear and surface roughness of different CAD/CAM monolithic ceramic materials opposing monolithic zirconia. The null hypothesis was that no difference would be found in the wear and surface roughness of different CAD/CAM monolithic ceramic materials opposing monolithic zirconia.

\section{MATERIALS AND METHODS}

According to Albashaireh et al, ${ }^{14}$ a sample size $(\mathrm{n}=8$ per group) had a $95 \%$ power with a significance level $(\alpha=.05)$ and an effect size $(\mathrm{F}=0.807)$ to test the null hypothesis that no difference would be found in the wear and surface roughness of 
different CAD/CAM monolithic ceramic materials opposing monolithic zirconia; this was increased to 27 specimens $(n=9)$ in each group to achieve more reliable results. In $95 \%$ (the power) of those experiments, $p$ was $<0.05$. A statistical software program (G* Power v3.1.9.22) was used to calculate the sample size. The materials evaluated in the present study are presented in Table 1. Twenty seven rectangular-shaped specimens $(14 \times 11 \times$ $1 \mathrm{~mm}$ ) were milled from different ceramic materials with a precision saw (Isomet 4000; Buehler, Lake Bluff, IL) under constant water irrigation and divided ( $n=9$ ) into 3 groups: group ZLS, zirconiareinforced lithium silicate; group $\mathrm{LD}$, lithium disilicate glass ceramic; and group ZR, 4-mol yttriastabilized tetragonal zirconia polycrystal (4Y-TZP). For group ZLS, specimens ( $n=9$ ) were cut from Celtra Duo blocks (LT, A2, C14) and crystallized in a calibrated porcelain furnace (Vacumat 40T; Vita Zahnfabrik, Bad Sackingen, Germany). For group LD, specimens $(n=9)$ were cut from IPS e.max CAD blocks (LT, BL1, C14) and crystallized in the same calibrated furnace. For group ZR, specimens (n=9) were cut $20 \%$ thicker from a partially sintered 4Y-TZP blank to compensate for the post sintering shrinkage of the enlarged specimens and sintered in a special sintering furnace (inFire HTC Speed; Dentsply Sirona, York, PA). Crystallization and sintering were done according to the manufacturers' instructions. The overall thickness of all specimens was checked and verified to a precision of $0.1 \mathrm{~mm}$ with digital calipers (Dial Caliper D; Aura-Dental, Aura an der Saale, Germany). For the antagonists, a digital 3D model of the antagonist was designed in a cone shape of 3-mm-diameter to simulate a zirconia cusp with a CAD software program (CEREC Primescan Software v.9; Dentsply Sirona, York, PA). The data obtained were sent to the milling machine (CEREC inLab MC X5; Dentsply Sirona, York, PA), where antagonists ( $\mathrm{n}=27$ ) were fabricated from a partially sintered 4Y-TZP blank (T14 mm, $\varnothing 98.5 \mathrm{~mm}$ ). The antagonists were sintered in the same sintering furnace.

All specimens $(n=27)$ were embedded in a custom-made teflon mold to match the jig of mastication simulator and secured in place by using autopolymerizing acrylic resin (Acrostone; Acrostone Co, Egypt). All specimens were sequentially wet polished by using rotating silicon carbide paper (240-, 400-, 600-grit papers; Buehler, Lake Bluff, IL), cleaned for 10 seconds by using a steam cleaner (EGV 18; Eurocem Srl, Milanese, Italy), and stored in distilled water at $37^{\circ} \mathrm{C}$ for 24 hours. Specimens were then steam cleaned, dried with absorbent paper then air dried, and weighted before wear testing. The 2-body wear test was performed in deionized water by using a dual axis mastication simulator (Robota modelach-09075dc-t; AdTech technology

TABLE (1) Materials evaluated

\begin{tabular}{|c|c|c|c|c|}
\hline Trade name & Classification & Composition & Manufacturer & Lot No. \\
\hline Celtra DUO & $\begin{array}{l}\text { Zirconia-reinforced } \\
\text { lithium silicate }\end{array}$ & $\begin{array}{c}58 \% \mathrm{SiO}_{2}, \mathrm{Li}_{2} \mathrm{O}, \mathrm{K}_{2} \mathrm{O}, \\
\mathrm{P}_{2} \mathrm{O}_{5}, \mathrm{Al}_{2} \mathrm{O}_{3}, 10 \% \mathrm{ZrO}_{2}, \mathrm{CeO}_{2} \text {, pigments }\end{array}$ & Dentsply Sirona & 16004681 \\
\hline $\begin{array}{l}\text { IPS e-max } \\
\text { CAD }\end{array}$ & $\begin{array}{l}\text { Lithium disilicate glass } \\
\text { ceramic }\end{array}$ & $\begin{array}{c}\mathrm{SiO}_{2} 57 \%-80 \%, \mathrm{Li}_{2} \mathrm{O} 11 \%-19 \%, \mathrm{~K}_{2} \mathrm{O} 0 \%-13 \% \\
\mathrm{P}_{2} \mathrm{O}_{5} 0 \%-11 \%, \mathrm{ZrO}_{2} 0 \%-8 \%, \mathrm{ZnO} 0 \%-8 \% \\
\mathrm{Al}_{2} \mathrm{O}_{3} 0 \%-5 \%, \mathrm{MgO} 0 \%-5 \%\end{array}$ & $\begin{array}{c}\text { Ivoclar vivadent } \\
\text { AG }\end{array}$ & X15204 \\
\hline $\begin{array}{l}\text { KATANA } \\
\text { Zirconia } \\
\text { STML }\end{array}$ & $\begin{array}{l}\text { 4-mol yttria-stabilized } \\
\text { tetragonal zirconia } \\
\text { polycrystal } \\
(4 \mathrm{Y}-\mathrm{TZP})\end{array}$ & $\begin{array}{c}\mathrm{ZrO}_{2}+\mathrm{HfO}_{2}+\mathrm{Y}_{2} \mathrm{O}_{3}>99 \%, \text { yttrium oxide }\left(\mathrm{Y}_{2} \mathrm{O}_{3}\right) \\
>4 \% \text {, hafnium oxide }\left(\mathrm{HfO}_{2}\right) \leq 5 \% \text {, other oxides } \\
\leq 1 \%\end{array}$ & Kuraray Noritake & DYBIR \\
\hline
\end{tabular}


Co. Ltd, Frankfurt, Germany) against the standard zirconia antagonists, according to the methodology described in a previous study. ${ }^{39}$ All specimens were subjected to a load of $49 \mathrm{~N}$ for 120,000 cycles at a frequency of $1.6 \mathrm{~Hz}$ to simulate 6 months of clinical use. ${ }^{10,40}$ After the wear testing, all specimens and zirconia antagonists were steam cleaned, dried with absorbent paper then air dried before weighing. A schematic presentation of the wear test configuration is shown in Figure 1 and the wear test parameters used are presented in Table 2.

TABLE (2) Wear test parameters used in this study

\begin{tabular}{|l|c|}
\hline \multicolumn{1}{|c|}{ Parameter } & Data \\
\hline Cycle preset & 120000 \\
\hline Cycle frequency & $1.6 \mathrm{~Hz}$ \\
\hline Cold/hot bath temperature & $5^{\circ} \mathrm{C} / 55^{\circ} \mathrm{C}$ \\
\hline Dwell time & $60 \mathrm{~s}$ \\
\hline Force & $49 \mathrm{~N}$ \\
\hline Vertical movement & $3 \mathrm{~mm}$ \\
\hline Lateral movement & $-0.7 \mathrm{~mm}$ \\
\hline Descent speed & $60 \mathrm{~mm} / \mathrm{s}$ \\
\hline Lifting speed & $60 \mathrm{~mm} / \mathrm{s}$ \\
\hline Feed speed & $40 \mathrm{~mm} / \mathrm{s}$ \\
\hline Return speed & $40 \mathrm{~mm} / \mathrm{s}$ \\
\hline
\end{tabular}

Weight loss was used to determine the quantitative wear data of ceramic specimens and opposing zirconia antagonists. By using an analytical balance (Quintix124-1S; Sartorius AG, Göttingen, Germany) with a precision of 0.0001 $\mathrm{g}$. The differences in weight of all specimens and zirconia antagonists before and after 120,000 cycles were calculated. A representative specimen from each ceramic group and its opposing zirconia antagonist was evaluated before and after the wear testing by using a scanning electron microscope (SEM) (Quanta 250 FEG; FEI SEM, Hillsboro, OR) at a working distance of $10 \mathrm{~mm}$ with an exciting voltage of $20 \mathrm{kV}$ at $\times 500$ magnification.

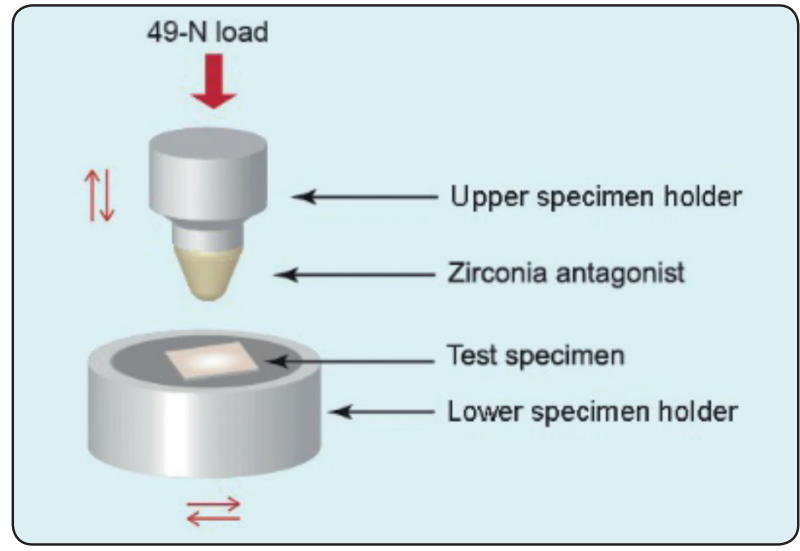

Fig. (1) Schematic presentation of wear testing

A digital image analysis software program (WSxM, v 5 develop 4.1, Nanotec, Electronica SL, San Diego, CA) coupled with a USB Digital microscope with an attached camera (Scope Capture Digital Microscope; Guangdong, China) at $\times 120$ magnification connected to a personal computer was used to obtain a 3D image of the surface profile of the specimens and their opposing zirconia antagonists by superimposing the 3D surfaces before and after the wear testing. All measured parameters were expressed in pixels; thus, program calibration was performed to convert the pixels into absolute units by comparing a ruler with a scale produced by the software. The average of heights (Ra) in $\mu \mathrm{m}$ were calculated by using the software program which were considered as reliable indices of surface roughness.

Data were presented as mean and standard deviation for values. Data were explored for normality and homogeneity of variances by using the ShapiroWilk and the Levene tests. One-way ANOVA followed by the Tukey post hoc tests were used to determine the difference among the mean values of the groups $(p=0.05)$. Intragroup comparisons where tested using paired t-test. Statistical analysis was performed by using a statistical software program (IBM SPSS Statistics, v26.0; IBM Corp). 


\section{RESULTS}

The mean values, standard deviations, and statistical results of the weight loss measured in $\mathrm{g}$ and surface roughness measured in $\mu \mathrm{m}$ were recorded for all ceramic groups and zirconia antagonists before and after 120,000 cycles and are listed in Table 3.

One-way ANOVA revealed significant amount of weight loss (wear) for all ceramic types $(p<0.05)$. No statistically significant differences were found between the different ceramic types when comparing their percentage change of weight $(p=0.544)$.

As for the antagonist, significant amount of weight loss was observed when opposed the different ceramic types $(p<0.05)$. However, no statistically significant difference was found when comparing the percentage change of the antagonist when opposed the difference ceramic materials $(p=0.115)$.

As for the surface roughness, one-way ANOVA revealed significant increase in surface roughness for all ceramic types after chewing simulation $(p<0.05)$. No statistically significant differences were found between the different ceramic types when comparing their percentage change roughness $(p=0.251)$.

As for the antagonist, significant amount of surface roughness increase was observed when opposed the different ceramic types $(p<0.05)$.

TABLE (3) Wear in $\mathrm{g}$, surface roughness in $\mu \mathrm{m}$ (mean values \pm SDs), and statistical results for all ceramic groups and their opposing zirconia antagonists

\begin{tabular}{|c|c|c|c|c|c|c|}
\hline \multirow{2}{*}{ Parameter } & \multirow{2}{*}{\multicolumn{2}{|c|}{ Measurement }} & \multicolumn{3}{|c|}{ (Mean values \pm SDs) } & \multirow{3}{*}{\begin{tabular}{|l} 
p Value \\
$<0.001$
\end{tabular}} \\
\hline & & & \multirow{2}{*}{$\begin{array}{c}\text { LD } \\
0.73 \pm 0.02^{\text {Ba }} \\
\end{array}$} & \multirow{2}{*}{$\begin{array}{c}\mathrm{ZR} \\
1.31 \pm 0.03^{\mathrm{Aa}} \\
\end{array}$} & \multirow{2}{*}{$\begin{array}{c}\text { ZLS } \\
0.66 \pm 0.01^{\mathrm{Ca}}\end{array}$} & \\
\hline \multirow{8}{*}{ Weight } & \multirow{4}{*}{ Specimen } & Before & & & & \\
\hline & & After & $0.72 \pm 0.03^{\mathrm{Bb}}$ & $1.30 \pm 0.03^{\mathrm{Ab}}$ & $0.66 \pm 0.01^{\mathrm{Cb}}$ & $<0.001$ \\
\hline & & $P$ & 0.033 & $<0.001$ & $<0.001$ & \\
\hline & & Change\% & $0.41 \pm 0.19^{\mathrm{A}}$ & $0.26 \pm 0.14^{\mathrm{A}}$ & $0.38 \pm 0.13^{\mathrm{A}}$ & 0.544 \\
\hline & \multirow{4}{*}{ Antagonist } & Before & $1.80 \pm 0.04^{\mathrm{Aa}}$ & $1.83 \pm 0.01^{\mathrm{Aa}}$ & $1.82 \pm 0.04^{\mathrm{Aa}}$ & 0.057 \\
\hline & & After & $1.79 \pm 0.04^{\mathrm{Ab}}$ & $1.81 \pm 0.02^{\mathrm{Ab}}$ & $1.80 \pm 0.04^{\mathrm{Ab}}$ & 0.888 \\
\hline & & $P$ & 0.003 & $<0.001$ & $<0.001$ & \\
\hline & & Change\% & $0.77 \pm 0.93^{\mathrm{A}}$ & $1.46 \pm 0.92^{\mathrm{A}}$ & $0.79 \pm 1.38^{\mathrm{A}}$ & 0.115 \\
\hline \multirow{8}{*}{$\begin{array}{c}\text { Surface } \\
\text { roughness }\end{array}$} & \multirow{4}{*}{ Specimen } & Before & $0.25 \pm 0.00^{\mathrm{Ba}}$ & $0.26 \pm 0.00^{\mathrm{Aa}}$ & $0.26 \pm 0.00^{\mathrm{Aa}}$ & $<0.001$ \\
\hline & & After & $0.25 \pm 0.00^{\mathrm{Bb}}$ & $0.26 \pm 0.00^{\mathrm{Ab}}$ & $0.25 \pm 0.00^{\mathrm{Bb}}$ & $<0.001$ \\
\hline & & $P$ & 0.001 & $<0.001$ & 0.003 & \\
\hline & & Change\% & $0.66 \pm 0.50^{\mathrm{A}}$ & $1.13 \pm 0.64^{\mathrm{A}}$ & $0.98 \pm 0.87^{\mathrm{A}}$ & 0.251 \\
\hline & \multirow{4}{*}{ Antagonist } & Before & $0.26 \pm 0.00^{\mathrm{Aa}}$ & $0.26 \pm 0.00^{\mathrm{Aa}}$ & $0.26 \pm 0.00^{\mathrm{Aa}}$ & 0.787 \\
\hline & & After & $0.26 \pm 0.00^{\mathrm{Ab}}$ & $0.26 \pm 0.00^{\mathrm{Ab}}$ & $0.26 \pm 0.00^{\mathrm{Ab}}$ & 0.980 \\
\hline & & $P$ & 0.001 & $<0.001$ & $0.001 *$ & \\
\hline & & Change\% & $0.80 \pm 0.48^{\mathrm{A}}$ & $0.93 \pm 0.43^{\mathrm{A}}$ & $0.93 \pm 0.75^{\mathrm{A}}$ & 0.858 \\
\hline
\end{tabular}

Different superscript uppercase within same row and lowercase letters within same column indicate significant difference $(p<0.05)$. LD, lithium disilicate; ZR, 4-mol yttria-stabilized tetragonal zirconia polycrystal (4Y-TZP); ZLS, zirconiareinforced lithium silicate; $S D$, standard deviation. 
However, no statistically significant difference was found when comparing the percentage change of the surface roughness of the antagonist when opposed the difference ceramic materials $(p=0.858)$.

Representative SEM images of the ceramic specimens' surface opposing zirconia antagonists are presented in Figure 2. All ceramic specimens showed fine scratches parallel with the sliding direction of antagonist on the worn surface indicating an abrasive wear mechanism. The ZR specimen displayed superficial parallel grooves with small fragments on the worn surface and a smooth pitted surface compared with other groups. The LD and ZLS specimens displayed deep grooves

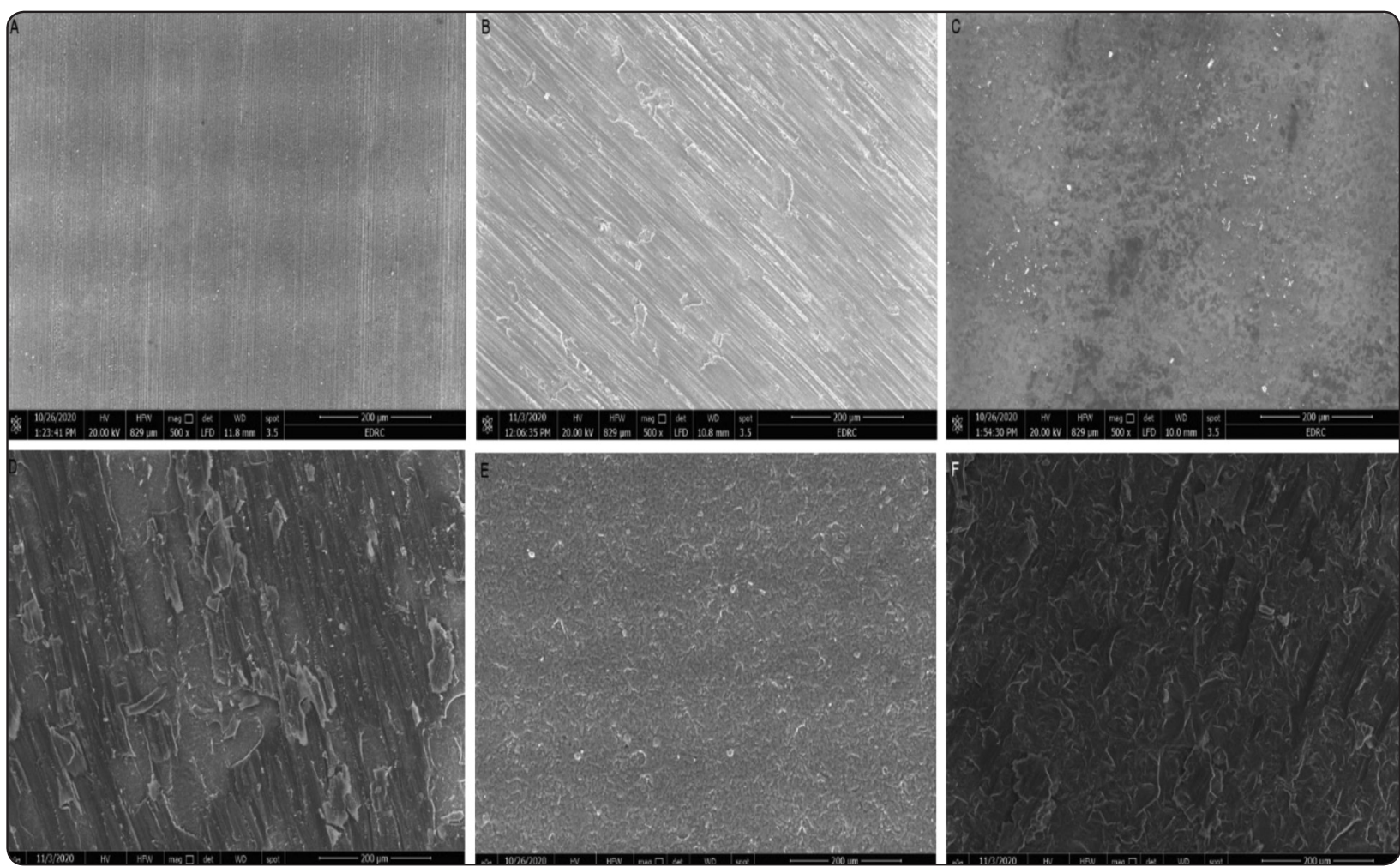

Fig. (2) Scanning electron microscope images of different ceramic materials opposing zirconia antagonists before (left) and after (right) wear testing. A, B, Monolithic zirconia (ZR). C, D, Lithium disilicate (LD). E, F, Zirconia-reinforced lithium silicate (ZLS). Original magnification $\times 500$.
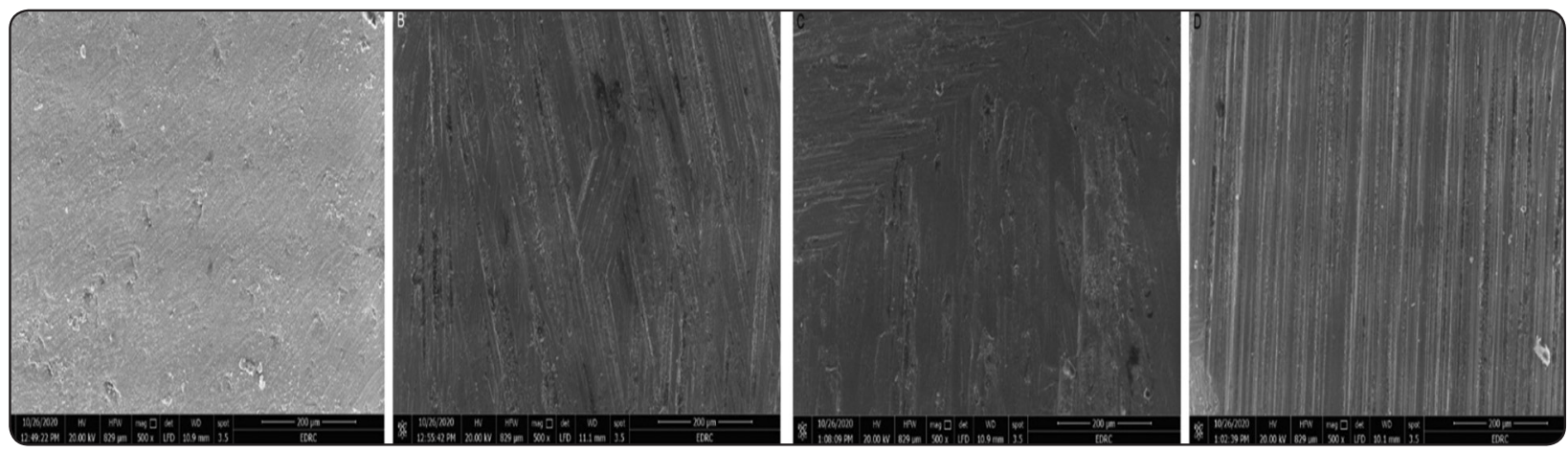

Fig. (3) Scanning electron microscope images of zirconia antagonists. A, Control. B, Opposing monolithic zirconia (ZR). C, Opposing lithium disilicate (LD). D, Opposing zirconia-reinforced lithium silicate (ZLS). Original magnification $\times 500$. 
with ceramic fragments on the worn surface and an irregular rough surface with small pits. The SEM images revealed also that all antagonists opposing ceramic specimens displayed increased surface roughness and pitting after wear testing; in addition, fine scratches and grooves in the sliding direction on the worn surface were observed (Fig. 3).
Representative 3D images of the surface profile of different ceramic materials and their opposing zirconia antagonists before and after wear testing are presented in Figures 4 and 5. The 3D images revealed that all ceramic specimens and their opposing zirconia antagonists displayed increased surface roughness after wear testing.
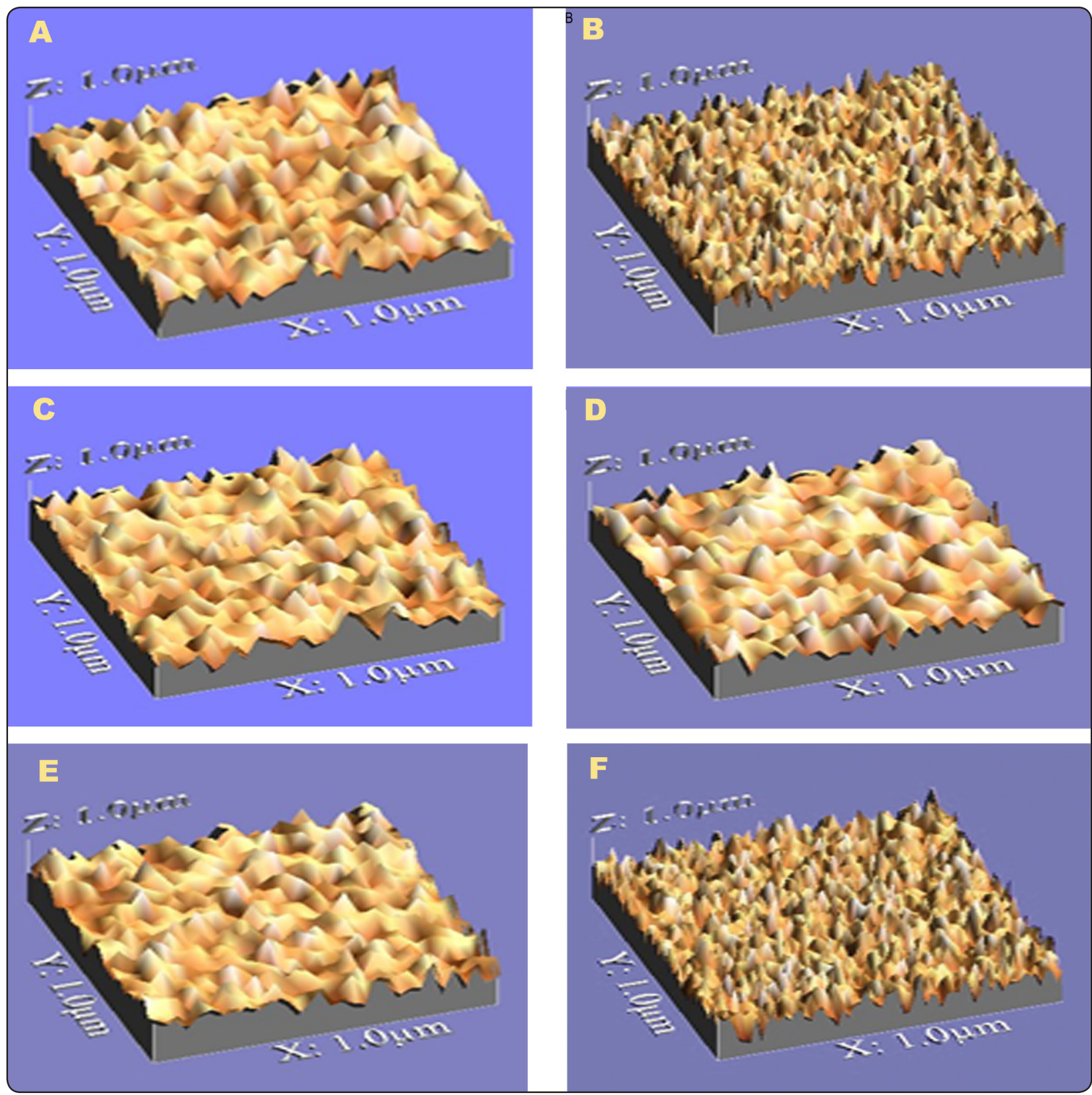

Fig. (4) Representative 3D images of the surface profile of different ceramic materials opposing zirconia antagonists before (left) and after (right) wear testing. A, B, Monolithic zirconia (ZR). C, D, Lithium disilicate (LD). E, F, Zirconia-reinforced lithium silicate (ZLS). 

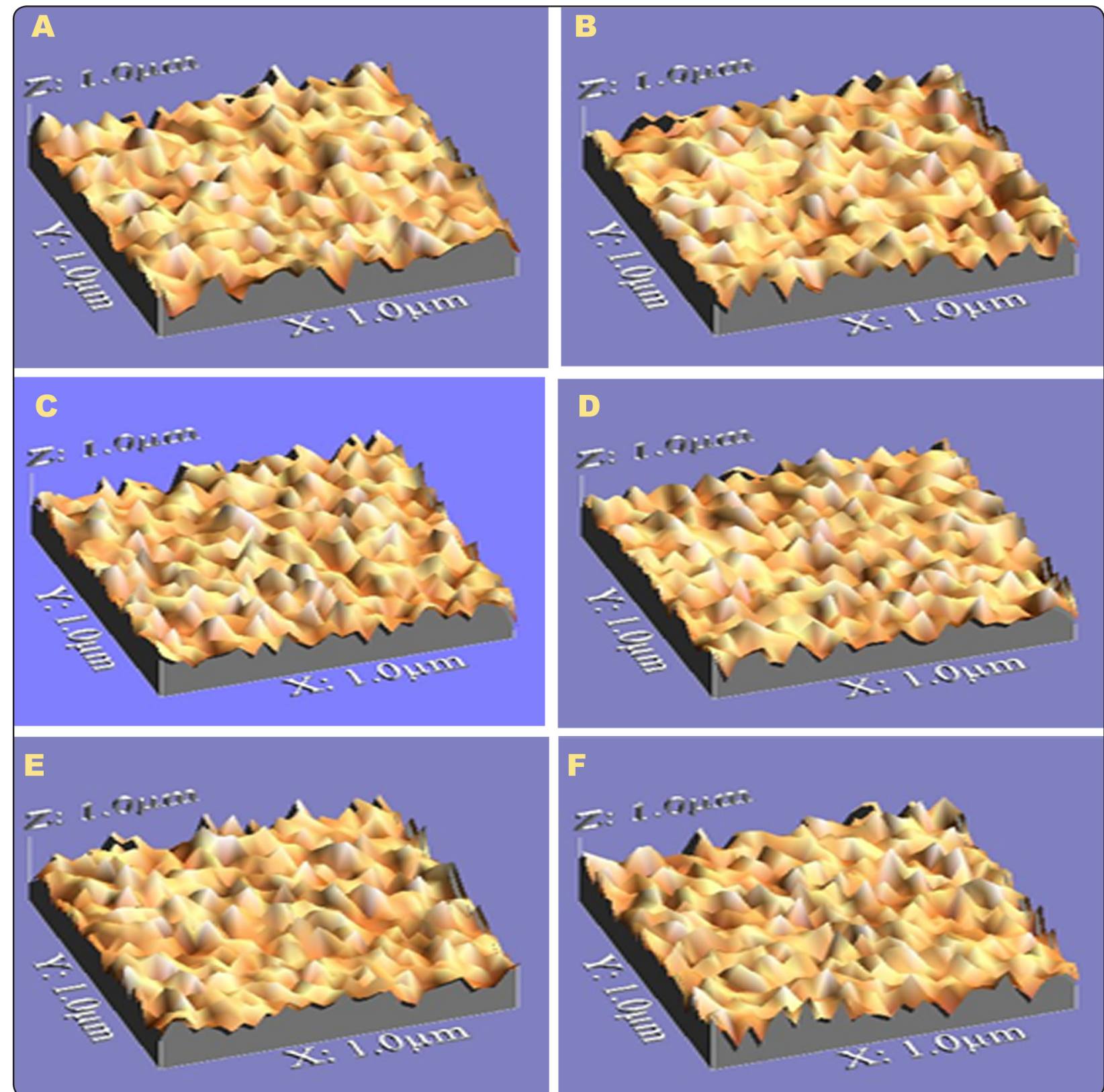

Fig. (4) Representative 3D images of the surface profile of different ceramic materials opposing zirconia antagonists before (left) and after (right) wear testing. A, B, Monolithic zirconia (ZR). C, D, Lithium disilicate (LD). E, F, Zirconia-reinforced lithium silicate (ZLS).

\section{DISCUSSION}

This in vitro study examined the wear and surface roughness of different $\mathrm{CAD} / \mathrm{CAM}$ monolithic ceramic materials opposing monolithic zirconia. The null hypothesis that no difference would be found regarding wear and surface roughness of different $\mathrm{CAD} / \mathrm{CAM}$ monolithic ceramic materials opposing monolithic zirconia was rejected. The obtained results showed significant differences in the wear (weight loss) of the $3 \mathrm{CAD} / \mathrm{CAM}$ monolithic ceramic specimens and the difference among all specimens was statistically significant; in addition, all specimens significantly wore their opposing zirconia antagonists. However, the type 
of ceramic did not have an influence on the wear amount. For the surface roughness, significant differences were found in the $3 \mathrm{CAD} / \mathrm{CAM}$ monolithic ceramic specimens after wear testing and no significant difference was observed between the lithium disilicate and the zirconia-reinforced lithium silicate specimens; in addition, all zirconia antagonists showed significantly increased surface roughness after wear testing. The SEM images revealed the increased wear for all ceramic groups and their opposing zirconia antagonists confirming the obtained results.

In this study, the wear 4Y-TZP could be attributed to the higher cubic content and lower fracture toughness of zirconia. ${ }^{38}$ In addition, the susceptibility of 4Y-TZP to hydrothermal aging in a water environment could degrade their elastic modulus and surface hardness due to spontaneous $t-m$ phase transformation and the formation of micro-cracks in the subsurface. ${ }^{41}$ The obtained results were consistent with those of previous studies testing wear of zirconia ceramics..$^{14,23}$ -

In the present study, the increased wear of lithium disilicate compared with 4Y-TZP is not only related to its lower hardness, but could also be attributed to its higher susceptibility to water-assisted slow crack growth (stress-corrosion) and lower fatigue threshold (fatigue wear) of $1.0 \mathrm{MPa} \cdot \mathrm{m}^{1 / 2}$, compared with $1.4 \mathrm{MPa} \cdot \mathrm{m}^{1 / 2}$ (40\% higher) for zirconia.,38 In addition, lithium disilicate contains 70 vol $\% \mathrm{Li}_{2} \mathrm{Si}_{2} \mathrm{O}_{5}$ crystals and $30 \mathrm{vol} \%$ of a silicate glass phase. ${ }^{10} \mathrm{In}$ many studies, dissolution of Si-O-Si glass network in a wet environment has been reported. ${ }^{3,38}$ This resulted in surface degradation and reduced surface hardness after wear testing. ${ }^{3}$

In this study, the slightly lower wear of zirconiareinforced lithium silicate when compared with lithium disilicate could be attributed to strengthening of the ceramic which prevented abrasive scratches. ${ }^{10}$ In addition, their reduced fracture toughness may be also responsible for their wear. ${ }^{1}$ In contrast, Belli et $\mathrm{al}^{42}$ reported similar wear values for the lithium disilicate and the zirconia-reinforced lithium silicate specimens which may be attributed to the same Young modulus of these materials.

A correlation between both wear and surface roughness was observed in this study because all ceramic materials with comparable surface roughness mean values had a significant effect on the antagonist wear after wear testing. This finding was in consistent with some authors ${ }^{27,36}$ who found that the surface roughness may predict wear. In contrast, Metzler et $\mathrm{al}^{43}$ reported that the early stage of wear depends on the surface condition of the ceramic material; nevertheless, the wear rate was affected by the nature of the material when the roughness disappeared with wear progression. Lack of a relationship between the wear rate and surface roughness was reported in different in vitro studies. ${ }^{28,29}$

Influencing wear factors of ceramics include microstructure of the material, crystal size, porosity, occlusal force, environment, abrasiveness of diet, frequency of mastication, and surface roughness. ${ }^{12,13}$ In addition, surface hardness, fracture toughness and elastic modulus may affect the wear rate of the ceramic materials. ${ }^{1,11}$ When ceramic slides against ceramic or enamel, wear occurs by subsurface microfractures and not by plastic deformation as with metals. ${ }^{3}$ The surface hardness of zirconia is approximately 1346 to $1368 \mathrm{~kg} / \mathrm{mm}^{2}$, compared with $703 \mathrm{~kg} / \mathrm{mm}^{2}$ for zirconia-reinforced lithium silicate, and $591 \mathrm{~kg} / \mathrm{mm}^{2}$ for lithium disilicate. ${ }^{10,11} \mathrm{It}$ has been reported that the antagonist wear against ceramics is not directly related to their hardness, but to depend more on their microstructure ${ }^{38}$ However, the correlation between wear and hardness for ceramic materials has not yet been established. ${ }^{3,11}$

Monolithic zirconia antagonists were used in the present study to achieve consistent and reliable results because their shape can be retained during the wear testing; therefore, limiting any changes in the antagonist surface which may affect the specimen wear. ${ }^{36,37}$ Several studies used enamel 
as an antagonist; however, the drawback of using enamel is the lack of test standardization because of the different degrees of mineralization, surface shape, and different thickness of enamel tissues from one patient to another resulting in a possible source of errors in the statistical outcomes. ${ }^{14}$

Based on the study by $\mathrm{Hu}$ et $\mathrm{al},{ }^{44}$ wear of the specimens and antagonists was measured by weight variations, but more sophisticated methods such as the micro computed tomography scanner ${ }^{45}$ or overlapping of profilometry image ${ }^{27}$ could result in more precise measurements and need to be studied in futures investigations.

Although studies on the wear of ceramic materials against zirconia are limited, the results of this in vitro study showed acceptable wear results. Limitations of this study included that the ceramic specimens were subjected 2-body wear against zirconia antagonists. Different results may have been found with enamel antagonists or with a 3-body wear test. Long-term clinical studies are required to confirm the results.

\section{CONCLUSIONS}

Based on the findings of this in vitro study, the following conclusions were drawn:

1. Zirconia as an antagonist showed abrasive wear to the opposed tested ceramics.

2. The different types of tested ceramics showed similar wear resistance when opposed to monolithic zirconia.

3. Zirconia as an antagonist caused an increase in the surface roughness of opposed ceramics.

\section{REFERENCES}

1. Ludovichetti FS, Trindade FZ, Werner A, et al: Wear resistance and abrasiveness of CAD/CAM monolithic materials. J Prosthet Dent 2018;120:318.e1-318.e8

2. Zhang F, Reveron H, Spies BC, et al: Trade-off between fracture resistance and translucency of zirconia and lithiumdisilicate glass ceramics for monolithic restorations. Acta Biomater 2019;91:24-34
3. Oh WS, Delong R, Anusavice KJ: Factors affecting enamel and ceramic wear: a literature review. J Prosthetic Dent 2002;87:451-459

4. Nassary Zadeh P, Lümkemann N, Sener B, et al: Flexural strength, fracture toughness, and translucency of cubic/tetragonal zirconia materials. J Prosthet Dent 2018;120:948-954

5. Quinn GD, Hoffman K, Quinn JB: Strength and fracture origins of a feldspathic porcelain. Dent Mater 2012; 28:502-511

6. Mitov G, Heintze SD, Walz S, et al: Wear behavior of dental Y-TZP ceramic against natural enamel after different finishing procedures. Dent Mater 2012;28:909-918

7. Sato TP, Anami LC, Melo RM, et al: Effects of surface treatments on the bond strength between resin cement and a new zirconia-reinforced lithium silicate ceramic. Oper Dent 2016;41:284-292

8. Lambrechts $\mathrm{P}$, Braem M, Vuylsteke-Wauters $\mathrm{M}$, et al: Quantitative in vivo wear of human enamel. J Dent Res 1989;68:1752-1754

9. Seghi RR, Rosenstiel SF, Bauer P: Abrasion of human enamel by different dental ceramics in vitro. J Dent Res 1991;70:221-225

10. D'Arcangelo C, Vanini L, Rondoni GD, et al: Wear properties of dental ceramics and porcelains compared with human enamel. J Prosthet Dent 2016;115:350-355

11. Mundhe K, Jain V, Pruthi G, et al: Clinical study to evaluate the wear of natural enamel antagonist to zirconia and metal ceramic crowns. J Prosthet Dent 2015;114:358-363

12. Faria AC, de Oliveira AA, Alves Gomes E, et al: Wear resistance of a pressable low-fusing ceramic opposed by dental alloys. J Mech Behav Biomed Mater 2014;32:46-51

13. Alves LMM, Contreras LPC, Campos TMB, et al: In vitro wear of a zirconium-reinforced lithium silicate ceramic against different restorative materials. J Mech Behav Biomed Mater 2019;100:103403

14. Albashaireh ZS, Ghazal M, Kern M: Two-body wear of different ceramic materials opposed to zirconia ceramic. J Prosthet Dent 2010;104:105-113

15. Zhang Z, Yi Y, Wang X, et al: A comparative study of progressive wear of four dental monolithic, veneered glassceramics. J Mech Behav Biomed Mater 2017;74:111-117 
16. Alraheam IA, Donovan TE, Rodgers B, et al: Effect of masticatory simulation on the translucency of different types of dental zirconia. J Prosthet Dent 2019;122:404-409

17. Mao L, Kaizer MR, Zhao M, et al: Graded ultra-translucent zirconia (5Y-PSZ) for strength and functionalities. J Dent Res 2018;97:1222-1228

18. Culp L, McLaren EA: Lithium disilicate: the restorative material of multiple options. Comp Cont Educ Dent 2010;31:716-720, 722, 724-725

19. Ataol AS, Ergun G: Repair bond strength of resin composite to bilayer dental ceramics. J Adv Prosthodont 2018;10:101-112

20. 1saka SE, Elnaghy AM: Mechanical properties of zirconia reinforced lithium silicate glass-ceramic. Dent Mater 2016;32:908-914

21. Fathy SM, Swain MV: In-vitro wear of natural tooth surface opposed with zirconia reinforced lithium silicate glass ceramic after accelerated ageing. Dent Mater 2018;34:551-559

22. Preis V, Behr M, Hahnel S: Influence of cementation on in vitro performance, marginal adaptation and fracture resistance of CAD/CAM fabricated ZLS molar crowns. Dent Mater 2015;31:1363-1369

23. D'Arcangelo C, Vanini L, Rondoni GD, et al: Wear evaluation of prosthetic materials opposing themselves. Oper Dent 2018;43:38-50

24. Wang L, Liu Y, Si W, et al: Friction and wear behaviors of dental ceramics against natural tooth enamel. J Eur Ceram Soc 2012;32:2599-2606

25. Stawarczyk B, Özcan M, Schmutz F, et al: Two-body wear of monolithic, veneered and glazed zirconia and their corresponding enamel antagonists. Acta Odontol Scand 2013;71:102-112

26. Mörmann WH, Stawarczyk B, Ender A, et al: Wear characteristics of current aesthetic dental restorative CAD/CAM materials: two-body wear, gloss retention, roughness and Martens hardness. J Mech Behav Biomed Mater 2013;20:113-125

27. Janyavula S, Lawson N, Cakir D, et al: The wear of polished and glazed zirconia against enamel. J Prosthet Dent 2013;109:22-29

28. Stawarczyk B, Frevert K, Ender A, et al: Comparison of four monolithic zirconia materials with conventional ones: Contrast ratio, grain size, four-point flexural strength and two-body wear. J Mech Behav Biomed Mater 2016;59:128-138

29. Figueiredo-Pina CG, Patas N, Canhoto J, et al: Tribological behavior of unveneered and veneered lithium disilicate dental material. J Mech Behav Biomed Mater 2016;53:226-238

30. Lawson NC, Bansal R, Burgess JO: Wear, strength, modulus and hardness of CAD/CAM restorative materials. Dent Mater 2016;32:e275-83

31. Culhaoglu AK, Park J: A comparison of the wear resistance and hardness of two different indirect composite resins with a ceramic material, opposed to human enamel. European J Gen Dent 2013;2:274-80

32. Sripetchdanond J, Leevailoj C: Wear of human enamel opposing monolithic zirconia, glass ceramic, and composite resin: an in vitro study. J Prosthet Dent 2014;112:1141-50

33. Amer R, Kürklü D, Kateeb E, et al: Three-body wear potential of dental yttrium-stabilized zirconia ceramic after grinding, polishing, and glazing treatments. J Prosthet Dent 2014;112:1151-1155

34. Preis V, Weiser F, Handel G, et al: Wear performance of monolithic dental ceramics with different surface treatments. Quintessence Int 2013;44:393-405

35. Lee A, Swain M, He L, et al: Wear behavior of human enamel against lithium disilicate glass ceramic and type III gold. J Prosthet Dent 2014;112:1399-1405

36. Ghazal M, Kern M: The influence of antagonistic surface roughness on the wear of human enamel and nanofilled composite resin artificial teeth. J Prosthet Dent 2009;101:342-349

37. Ghazal M, Kern M: Wear of human enamel and nanofilled composite resin denture teeth under different loading forces. J Oral Rehabil 2009;36:58-64

38. Zhang F, Spies BC, Vleugels J, et al: High-translucent yttria-stabilized zirconia ceramics are wear-resistant and antagonist-friendly. Dent Mater 2019;35:1776-1790

39. D'Arcangelo C, Vanini L, Rondoni GD, et al: Wear properties of a novel resin composite compared to human enamel and other restorative materials. Oper Dent 2014;39:612-618

40. Heintze SD, Zappini G, Rousson V: Wear of ten dental restorative materials in five wear simulators--results of a round robin test. Dent Mater 2005;21:304-317 
41. Gaillard Y, Jiménez-Piqué E, Soldera F, et al: Quantification of hydrothermal degradation in zirconia by nanoindentation. Acta Mater 2008;56:4206-4216

42. Belli R, Wendler M, de Ligny D, et al: Chairside CAD/ CAM materials. Part 1: Measurement of elastic constants and microstructural characterization. Dent Mater 2017; 33:84-98

43. Metzler KT, Woody RD, Miller AW 3rd, et al: In vitro investigation of the wear of human enamel by dental porcelain. J Prosthet Dent 1999;81:356-364

44. Hu X, Zhang Q, Ning J, et al: Study of two-body wear performance of dental materials. J Natl Med Assoc 2018;110:250-255

45. Kaizer MR, Gierthmuehlen PC, Dos Santos MB, et al: Speed sintering translucent zirconia for chairside onevisit dental restorations: optical, mechanical, and wear characteristics. Ceram Int 2017;43:10999-11005 